\title{
RESEARCH OF ALTERATION OF PORTLANDITE CRYSTALS HABIT AS A FACTOR OF STRUCTURE FORMATION CONTROL FOR LIME-CONTAINING BINDERS
}

\author{
Yaroslav Yakymechko \\ Department of Chemical Technology of Silicate Materials \\ Lviv Polytechnic National University \\ 12 S. Bandery str., Lviv, Ukraine, 79013 \\ yayakym@gmail.com \\ Myroslav Sanytsky \\ Department of Building Production \\ Lviv Polytechnic National University \\ 12 S. Bandery str., Lviv, Ukraine, 79013 \\ msanytsky@ukr.net \\ Bohdan Chekanskyi \\ Department of Chemical Technology of Silicate Materials \\ Lviv Polytechnic National University \\ 12 S. Bandery str., Lviv, Ukraine, 79013 \\ chbb1992@gmail.com
}

\begin{abstract}
The processes of $\mathrm{CaO}$ hydration have been investigated under various temperature conditions and while introducing of $\mathrm{H}_{3} \mathrm{PO}_{4}$, $\mathrm{H}_{2} \mathrm{SO}_{4}, \mathrm{H}_{2} \mathrm{SiO}_{3}, \mathrm{H}_{3} \mathrm{BO}_{3}$ and their sodium salts into water. The binding composites were obtained based on thin-grinded quicklime with $95.6 \%$ of active $\mathrm{CaO}$ and $\mathrm{MgO}$. The phase composition of the hydration products were clearly confirmed mainly by XRD and thermal analyses. Under cryogenic conditions (temperature $-4{ }^{\circ} \mathrm{C}$ ) the rate of the reaction between $\mathrm{CaO}$ and $\mathrm{CO}_{2}$ of the air increased and extra amount of calcite was formed. During $\mathrm{CaO}$ hydration with the introduction of additives containing $\mathrm{SO}_{4}{ }^{2-}$ and $\mathrm{BO}_{3}{ }^{3-}$ anions the formation of Portlandite crystals (mainly of lamellar habit) was observed. Rietveld method demonstrates the increase in half-width of 01-2, 02-1, 01-3, 022 and 122 reflections in Portlandite stone indicating the occurrence of stresses that alter the rate of crystals growth in definite directions. The formation of $\mathrm{Ca}(\mathrm{OH})_{2}$ fine crystals of hexagonal lamellae shape results in the increase of their surface, the contact area and bond strength that leads, in its turn, to the increase in mechanical strength of the structure.
\end{abstract}

Keywords: calcium oxide, Portlandite, crystals habit, limestone, hydration hardening.

\section{Introduction}

The binders based on grinded quicklime are rarely used because $\mathrm{CaO}$ hydration under increased exothermicity is accompanied by significant temperature deformations of the solid phase particles and new formations hydration with simultaneous destruction of the formed structure. As a result of these phenomena the quicklime hydration is finished by the formation of powdered hydralime. The main reason for its formation is high thermodynamically unstable state of calcium oxide, as well as the peculiarities of its crystal lattice structure [1-3].

However it should be noted that the principle of artificial stone production in the form of spatial system of strongly bonded new formations is widely used in the building industry by means of monohydrates crystallization method $[4,5]$. This principle is realized in gypsum, magnesia and other binders of monomineral composite. Moreover, the hardening processes of monohydrate systems have the same regularities. From this point of view it should be possible to produce the stone during calcium oxide hydration and Portlandite crystallization. The obtaining of binders from metal oxides is described [6]. According to this the oxide of any metal exhibits binding properties under certain rate of its interaction with water. 
An important criterion that provides the obtaining of high-strength stone based on calcium oxide is a controlled process of its hydration without rapid heat release and structure destruction. Theoretical bases of the reduction of $\mathrm{CaO}$ hydration activity are developed in [7-9]. The following ways of rate control are examined there: removal of hydration heat, usage of chemical reagents limiting water access to the surface of $\mathrm{CaO}$ particles, method of reduction of $\mathrm{CaO}$ hydration activity via introduction of fine strong-polarizing cations $\mathrm{Si}^{4+}, \mathrm{Al}^{3+}, \mathrm{Fe}^{3+}$ while burning and other.

The strength of the stone based on quicklime achieves $30.2 \mathrm{MPa}$ at $0{ }^{\circ} \mathrm{C}$ after 7 days [10]. The reasons are the absence of system overheating, increased solubility of $\mathrm{Ca}(\mathrm{OH})_{2}$ at low temperatures and formation of Portlandite large crystals. It should be noted that crystals habit and morphology have the significant influence on the properties of lime mortars (viscosity, mobility, convenient placing) and determine, in its turn, the physico-mechanical properties of the lime stone. During long storage (2-3 years) of lime paste the recrystallization of Portlandite prismatic crystals occurs and crystals of lamellar habit are formed due to the increased dilution rate along planes (0001) [11]. Such crystals have high reactivity, plasticity and water storage capacity.

The main distinction of $\mathrm{CaO}$ hydration hardening (physico-chemical process under which the lime stone is directly formed during interaction between $\mathrm{CaO}$ and water) is the presence of considerable supersaturation and geometric selection of crystal phase. At the same time Portlandite is crystallized in the form of thin hexagonal lamellae and the system mechanical strength is provided by adhesion between separate crystallites along cleavage planes due to Van-der-Waals bond [12-14].

The aim of the article is the development of theoretical foundations of hydration process and hardening of monomineral binder - calcium oxide.

\section{Materials and Methods}

For investigations we used the commercial lime with the following characteristics: content of active $\mathrm{CaO}$ and $\mathrm{MgO}-95.6 \mathrm{wt} \%$; time for achieving maximal temperature of liming - 5 min.; maximal temperature of liming $-98{ }^{\circ} \mathrm{C}$. The processing characteristics are given in Table 1. Selected properties have a decisive influence on the reaction rate of $\mathrm{CaO}$ and $\mathrm{H}_{2} \mathrm{O}$ and physico-mechanical properties of the stone from portlandite.

Table 1

Processing characteristics of quicklime

\begin{tabular}{cc}
\hline Index & Value \\
\hline $\mathrm{CaO}$ total content, wt \% & 95.6 \\
$\mathrm{MgO}$ content, wt \% & 0.9 \\
Insoluble impurities, wt \% & 0.9 \\
$\mathrm{CO}_{2}$ content, wt \% & 1.7 \\
$\mathrm{H}_{2} \mathrm{O}$ content, wt \% & 0.9 \\
Total, wt \% & 100.0 \\
Free $\mathrm{CaO}_{\text {theor. }}, \mathrm{wt} \%$ & 90.8 \\
$\mathrm{CaCO}_{3}$ content, wt \% & 3.8 \\
$\mathrm{Ca}(\mathrm{OH})_{2}$ content, wt \% & 3.6 \\
Time of achieving hydration degree $80 \%(\mathrm{EN} 459)$, min. & 3
\end{tabular}

Physico-mechanical tests were carried out for the samples of $2 \times 2 \times 8 \mathrm{~cm}$ size after $3,7,14$ and 28 days which were hardened under normal conditions $\left(\mathrm{t}=20^{\circ} \mathrm{C}\right)$ and in the special forms limiting the system expansion. The reason for the mentioned curing conditions is the fact that during $\mathrm{CaO}$ hydration a large amount of heat is evolved, that can destroy the structure. When hardening takes place in small forms and in limited extent such phenomena are not observed.

Additionally we determined standard consistence of the lime paste. As the standard paste density we accepted such consistency of the paste when a needle of standard Vicat apparatus (Ukraine) penetrated into it by $20 \pm 5 \mathrm{~mm}$ for $30 \mathrm{~s}$. Characteristics of standard consistence are given in [15]. 
The yield of the lime paste with the standard consistency was determined in liters per $1 \mathrm{~kg}$ of quicklime during wet liming of grinded quicklime (weight $200 \mathrm{~g}$ ). The size of hydralime particles were determined by measuring the rate of suspension sedimentation and continuous weighing using torsion balance.

By means of X-ray analysis we determined the phase composition of the investigated materials, binders and the stone on their basis. X-ray diffractometer DRON 4.0 (Ukraine) with CuK $\alpha$ radiation of X-ray tube was used. The samples were prepared using powder method [16]. To stop the hydration process the samples were treated by alcohol and ether and dried under vacuum.

Differential thermal analysis (DTA) was used to determine the content of individual phases (Portlandite, calcite) and impurities in the composition of quicklime and hydralime, as well as in the hydration products of the composite binders. Derivatogramms were recorded using Paulik-PaulikErdey derivatograph Q-1500D (Hungary) with heating rate of $10{ }^{\circ} \mathrm{C} / \mathrm{min}$. Microparticles of hydrated and non-hydrated lime were studied using electron microscope JEM-100CX II (TOKIO BOEKI, Japan). The sample was mixed with acetone in an ultrasonic mixer and then the mixture was placed over carbon film. Microdifraction images were filmed with microscope camera of $55 \mathrm{~cm}$ length.

The influence of chemical reagents on the crystals structure and Portlandite chemical characteristics were evaluated using Rietveld method [17].

\section{Results and Discussion}

The hydration processes of $\mathrm{CaO}$ were investigated under cryohydration regime. Thin-grinded lime shuttered by water at $+4{ }^{\circ} \mathrm{C}$ was cooled till $0{ }^{\circ} \mathrm{C}$. Under such conditions the rate of $\mathrm{CaO}$ with water interaction is very low.

Using DTA results, we calculate mass losses of the samples at different hardening temperatures (Table 2). The thermodynamic estimation of the strength is carried out according to the procedure described in [18] on the basis of obtained experimental data. The change of system energy output is estimated using energy reserve (ER), the value of which depends on the nature and amount of hydrated phases. So, the higher amount of energy is released, the higher values of ER and stone strength are obtained. $\mathrm{CaO}$ hardening at $-4{ }^{\circ} \mathrm{C}$ is accompanied by two exothermal reactions with $\mathrm{Ca}(\mathrm{OH})_{2}$ formation and carbonization. At negative temperatures the increase in carbonization rate is observed providing the increase in $\mathrm{CaO}$ hydration degree and the decrease in volume nonuniformity accompanied by the decrease in strength.

Table 2

Thermal analysis results

\begin{tabular}{|c|c|c|c|c|c|c|c|}
\hline \multirow{2}{*}{ Hardening conditions } & \multicolumn{2}{|c|}{ Hardening time, days } & \multicolumn{2}{|c|}{ Endoeffects, ${ }^{\circ} \mathrm{C}$} & \multicolumn{2}{|c|}{ Mass losses, wt \% } & \multirow{2}{*}{$\begin{array}{c}\text { Total } \\
\text { mass loss, \% }\end{array}$} \\
\hline & $\mathbf{0}^{\circ} \mathrm{C}$ & $-4^{\circ} \mathrm{C}$ & I & II & I & II & \\
\hline At the air (blank test) & 28 & - & 510 & 845 & 23.4 & 6.9 & 30.3 \\
\hline In water $\left(+1^{\circ} \mathrm{C}\right)$ & 28 & - & 515 & 830 & 28.7 & 2.5 & 31.2 \\
\hline At the air & - & 28 & 508 & 865 & 9.1 & 28.7 & 38.8 \\
\hline At the air & 1 & 27 & 506 & 870 & 10.0 & 29.2 & 39.2 \\
\hline
\end{tabular}

During $\mathrm{CaO}$ hydration the system volume increases owing to peptization. As a result, the strength is reduced or the lime stone is destroyed. The internal hydration processes, which are intensified by dispersive phenomena, play the main role here. Under $\mathrm{CaO}$ hydration in the limited volume the rate of $\mathrm{CaO}$ interaction decreases and strong lime stone is formed.

To check the mentioned hypothesis we carried out physico-mechanical tests under compressed conditions of hardening. To retard the reaction of $\mathrm{CaO}$ hydration we added saccharose in amount of $0.5 \mathrm{wt} \%$. This additive is an effective liming inhibitor.

The obtained results (Table 3) show that during lime hardening under the limited volume conditions the lime stone is condensed, i. e. stone strength and its average density increase. The increase in strength occurs due to the increase in intermolecular contacts in the Portlandite crys- 
tals. The obtained stone is characterized by high density and absence of air pores. Determination of porosity by kerosene saturation shows that number of pores decreases in time.

The lime stone microstructure under compressed conditions of hardening is characterized by absence of accurately faceted crystals. The particles of ball-like shape of $5019 \mu \mathrm{m}$ size predominate. After 28 days we observed enlargement and accretion of the particles resulting in the decrease of porosity and the increase of average density. Later (after 84 days) the Portlandite recrystallization occurs and columnar crystals are formed with the diameter of 5-8 $\mu \mathrm{m}$ and height of $22-25 \mu \mathrm{m}$ which are packed in the pores with the diameter of 100-120 $\mu \mathrm{m}$.

Table 3

Physico-mechanical properties of the lime stone (hardening under compressed conditions)

\begin{tabular}{ccccc}
\hline Index & Units & \multicolumn{3}{c}{ Values after days } \\
& & $\mathbf{3}$ & $\mathbf{1 4}$ & $\mathbf{2 8}$ \\
\hline Compression strength & $\mathrm{MPa}$ & 15.6 & 25.5 & 38.7 \\
Water absorption & $\%$ & 10.5 & 8.9 & 6.2 \\
Average density & $\mathrm{g} / \mathrm{cm}^{3}$ & 1.89 & 1.92 & 1.98 \\
Accessible porosity & $\mathrm{wt} \%$ & 9.8 & 12.4 & 5.3 \\
Total porosity & wt $\%$ & 13.5 & & 11.8
\end{tabular}

The habit of Portlandite crystals varies in the limited volume. In the absence of free space the direction of $\mathrm{Ca}(\mathrm{OH})_{2}$ crystallization is changed and arc-like configurations with joint centre are formed.

The processes of structure formation are persistent if the lime stone does not contain free $\mathrm{CaO}$. The limited volume, presence of capillary moisture and Portlandite thin-grinded particles of different shapes set up thermodynamical conditions for recrystallization followed by formation of perfect crystal forms [19]. The Portlandite crystals size increases in accordance with the known principle of Gibbs-Curie-Wulff [20], when the surface of the particles (hydrates) takes a shape that corresponds to the minimal surface energy. This principle allows to determine the crystal symmetry after external influence on it because the crystal changes its point orientation in such a way, that only elements of symmetry joint with those of external influence are preserved. Thus, after 360 days we observe the formation of parallel-accreted columnar crystals with the height of 50-60 $\mu \mathrm{m}$. The direction of their growth is perpendicular to compression force that restricts expansion. So, the compressed conditions alter the morphology and habit of Portlandite crystals, as well as the direction of their growth and sizes. By means of physico-mechanical tests we proved that Portlandite crystals densely fill the space and form the stone with compression strength of 50.0-60.0 MPa.

Calcium oxide hydration is accompanied by the decrease in free water amount and increase in the solid phase volume. However, the total volume of the hydrated system decreases due to contraction. We studied contraction during lime hydration with inhibitors of different nature. U-manometer with border of measurements $0 \ldots 100 \mathrm{~mm}$ water column (Ukraine) was used with water: lime ratio equal to 1.0. During $\mathrm{CaO}$ hydration without additives the contraction value is changed according to the same law as the system temperature changes (Fig. 1). So, the dependence of contraction value on the lime paste yield is directly proportional and the value may be used as an effective estimator for additive influence on $\mathrm{CaO}$ hydration hardening.

The rate of $\mathrm{CaO}$ hydration under the conditions of limited volume decreases due to the smaller contact area of water with internal areas of lime particles during compressive forces occurrence [21]. The same effect is obtained during $\mathrm{CaO}$ hydration under vacuum. The results show that rarefaction about $160 \mathrm{~mm} \mathrm{H}_{2} \mathrm{O}$ is appeared in the closed volume as a result of contraction. Using thermal analysis, we determined the rate of heat release in the system $\mathrm{CaO}-\mathrm{H}_{2} \mathrm{O}$ at different values of initial rarefaction and content of free $\mathrm{CaO}$ (Table 4). Varying the initial rarefaction, we may control the rate of interaction between $\mathrm{CaO}$ and water. At $100 \mathrm{~mm} \mathrm{H}_{2} \mathrm{O}$ there are favourable conditions for hydration hardening because maximum temperature of the system does not exceed $55{ }^{\circ} \mathrm{C}$, 
i. e. overheating and intensive evaporation (which destroy the system) do not occur. The rarefaction of $100-150 \mathrm{~mm} \mathrm{H}_{2} \mathrm{O}$ is achieved due to the contraction during $\mathrm{CaO}$ hydration in the closed volume.

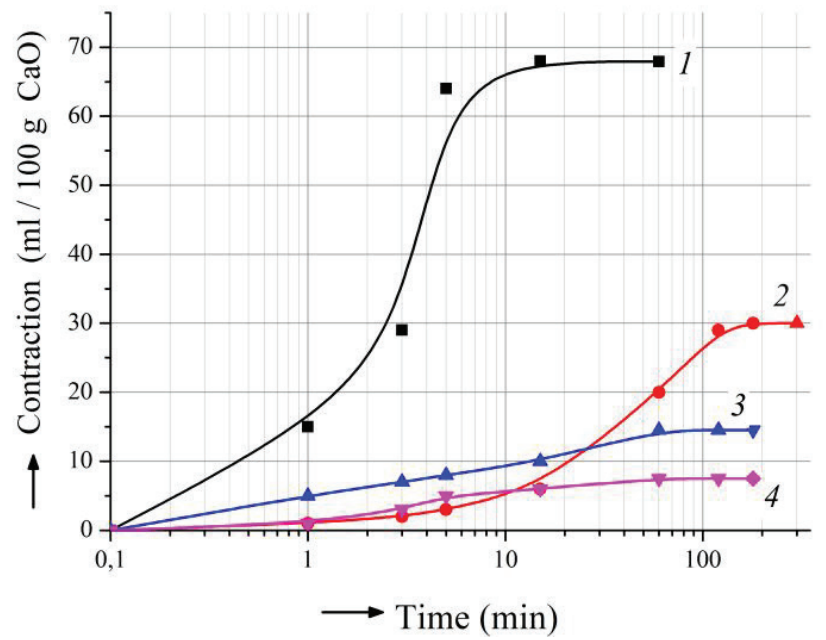

Fig. 1. Influence of additives on contraction value during $\mathrm{CaO}$ hydration:

1 - without additives; $2-1 \%$ of saccharose; $3-5 \%$ of $\mathrm{CaSO}_{4} \cdot 2 \mathrm{H}_{2} \mathrm{O} ; 4-1 \%$ of $\mathrm{Na}_{2} \mathrm{~B}_{4} \mathrm{O}_{7}$

Table 4

Effect of initial refraction value on the rate of $\mathrm{CaO}$ hydration $(\mathrm{L} / \mathrm{W}=1.0)$

\begin{tabular}{|c|c|c|c|c|c|}
\hline \multirow{2}{*}{$\begin{array}{l}\text { Rarefaction, } \\
\text { mm } \mathrm{H}_{2} \mathrm{O}\end{array}$} & \multirow{2}{*}{$\begin{array}{l}\text { Time for achieving } \\
\text { maximum temperature, min. }\end{array}$} & \multirow{2}{*}{$\begin{array}{l}\text { Maximum } \\
\text { temperature, }{ }^{\circ} \mathrm{C}\end{array}$} & \multicolumn{3}{|c|}{ Content of free $\mathrm{CaO}$, wt $\%$, after hrs } \\
\hline & & & 3 & 24 & 72 \\
\hline 50 & 30 & 78 & 3.6 & 0.2 & - \\
\hline 100 & 75 & 54 & 7.8 & 2.5 & 0.5 \\
\hline 150 & 186 & 45 & 25.1 & 10.7 & 5.8 \\
\hline 200 & 620 & 32 & 54.7 & 28.7 & 15.6 \\
\hline 250 & 846 & 25 & 68.5 & 40.6 & 36.8 \\
\hline
\end{tabular}

We may change the rate of $\mathrm{CaO}$ hydration affecting the individual stages of the process. The effective technological approach is the introduction of chemical additives to the binder composition. Such additives increase the time for achieving maximum temperature till 2-3 hours. However this effect is obligatory but not only one requirement for creation conditions of $\mathrm{CaO}$ hydration hardening. The additives of different nature may also change the conditions of Portlandite crystallization, undergo the reactions with the initial components and alter the final properties of the hydrated products $[22,23]$.

The results of physico-mechanical tests of the lime stone with different additives are represented in Table 5. To exclude the interaction between acids and $\mathrm{CaO}$ or $\mathrm{Ca}(\mathrm{OH})_{2}$ we conducted the similar experiments with sodium salts of the corresponding acids.

According to the additives effect on the strength of the lime stone they are situated in a row (by anion type): $\mathrm{PO}_{4}^{3-} \rightarrow \mathrm{SO}_{4}{ }^{2-} \rightarrow \mathrm{SiO}_{4}{ }^{4-} \rightarrow \mathrm{BO}_{4}{ }^{5-}$. At free $\mathrm{CaO}$ content of $<1.0 \mathrm{wt} \%$ (the data of petrographic analysis) the stone strength after 14 days is higher compared with that without additives. At the same time the presence of $\mathrm{BO}_{4}{ }^{-}$anions in the solution leads to 2.5-3.0 times increase in the stone strength for all times of hardening.

In the presence of investigated additives the rate of $\mathrm{CaO}$ hydration varies insignificantly due to the peculiarities of Portlandite crystallization and change in its morphology.

Using quantitative X-ray analysis we examined the phase composition of the lime stone with $\mathrm{H}_{3} \mathrm{BO}_{3}$ after hardening (14 days) at $+4{ }^{\circ} \mathrm{C}$. By means of Rietveld method we determined that calcite content was $4.6 \mathrm{wt} \%$ for the samples without additives and $6.0 \mathrm{wt} \%$ - for the samples with $\mathrm{H}_{3} \mathrm{BO}_{3}$. While 
adding $\mathrm{H}_{3} \mathrm{BO}_{3}$ we observe the increase in reflection intensity (001) due to the alteration in Portlandite crystals habit and appearance of tension in the surface layers of crystallites in the presence of $\mathrm{B}^{3+}$ ions.

Moreover, we observe the increase in half-width of reflections 01-2, 02-1, 01-3, 022 and 122 in Portlandite stone obtained during $\mathrm{CaO}$ hydration in the presence of $\mathrm{SO}_{4}{ }^{2-}, \mathrm{SiO}_{4}{ }^{4-}$ and $\mathrm{BO}_{4}{ }^{5-}$ anions (Fig. 2). The tension in the surface layers of $\mathrm{Ca}(\mathrm{OH})_{2}$ crystals change their growth rates in definite directions. In the presence of $\mathrm{SO}_{4}^{2-}$ anions the growth rate in the direction (001) is lower than that in the direction (100). As a result, Portlandite is crystallized in the shape of hexagonal lamellae. The main reason for such distinction is the difference between surface energy of the crystals in different directions.

Table 5

Effect of additives on the lime stone strength $(\mathrm{L} / \mathrm{W}=0.50)$

\begin{tabular}{ccc}
\hline $\begin{array}{c}\text { Additive } \\
(\mathbf{1 . 0} \text { mol \%) }\end{array}$ & \multicolumn{2}{c}{ Compression strength, MPa after days } \\
\hline- & 7 & $\mathbf{1 4}$ \\
$\mathrm{H}_{3} \mathrm{PO}_{4}$ & 4.0 & -05 \\
$\mathrm{H}_{2} \mathrm{SO}_{4}$ & 1.31 & 5.35 \\
$\mathrm{H}_{2} \mathrm{SiO}_{3}$ & 2.52 & 5.12 \\
$\mathrm{H}_{3} \mathrm{BO}_{3}$ & 4.75 & 8.13 \\
$\mathrm{Na}_{3} \mathrm{P}_{2} \mathrm{O}_{7}$ & 7.75 & - \\
$\mathrm{Na}_{2} \mathrm{SO}_{4}$ & 0.29 & 2.73 \\
$\mathrm{Na}_{2} \mathrm{SiO}_{3}$ & 1.86 & 2.51 \\
$\mathrm{Na}_{2} \mathrm{~B}_{4} \mathrm{O}_{7}$ & 1.94 & 7.78
\end{tabular}

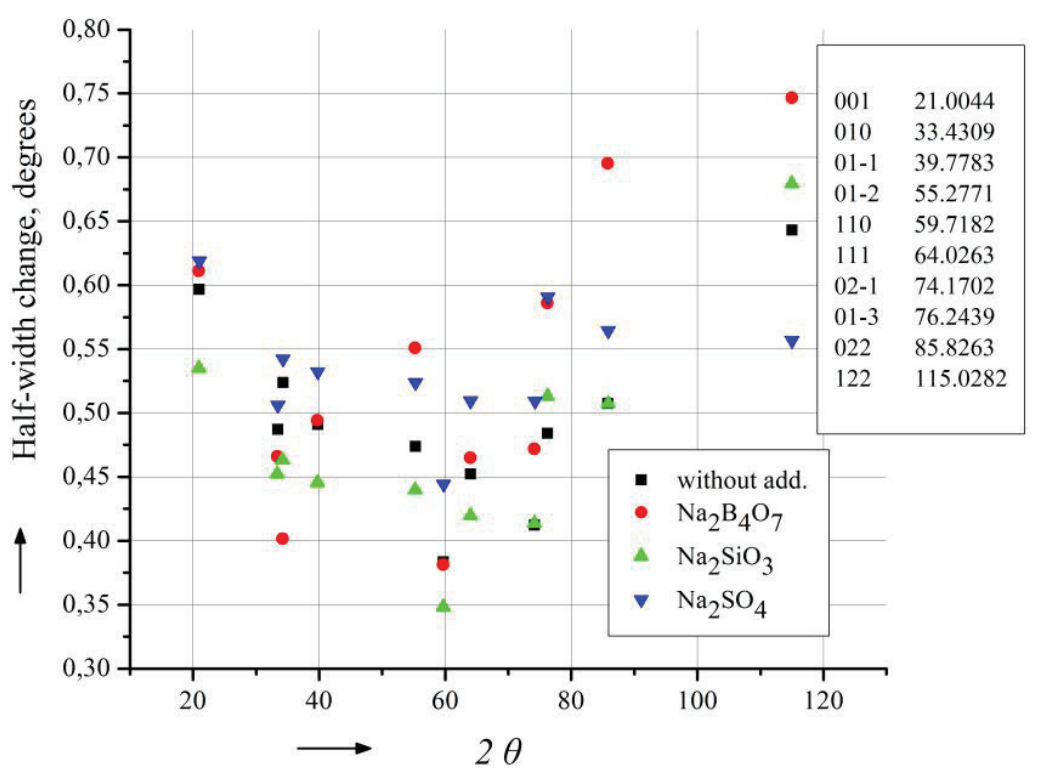

Fig. 2. Change of reflections half-width during $\mathrm{CaO}$ hydration without additives and while adding $2.0 \mathrm{~mol} \%$ of $\mathrm{Na}_{2} \mathrm{~B}_{4} \mathrm{O}_{7}, \mathrm{Na}_{2} \mathrm{SiO}_{3}$ and $\mathrm{Na}_{2} \mathrm{SO}_{4}$

Scanning Electron Microscopy investigations exhibit the considerable effect of $\mathrm{SO}_{4}^{2-}, \mathrm{SiO}_{4}^{4-}$ and $\mathrm{BO}_{4}^{5-}$ anions on the crystals morphology and habit (Fig. 3). In the presence of $\mathrm{BO}_{4}^{5-}$ anions the stone microstructure is represented by Portlandite in the shape of densely associated lamellae with the side ratio of 5.5-8.5. During $\mathrm{CaO}$ hydration in the solution with anionic groups $\mathrm{SO}_{4}{ }^{2-}$ we observe the increase in number of lamellar crystals associated into parallel growths. The presence of $\mathrm{SiO}_{4}{ }^{4-}$ anions sharply changes the morphology of Portlandite crystals which are crystallized as aggregates of irregular shape. 


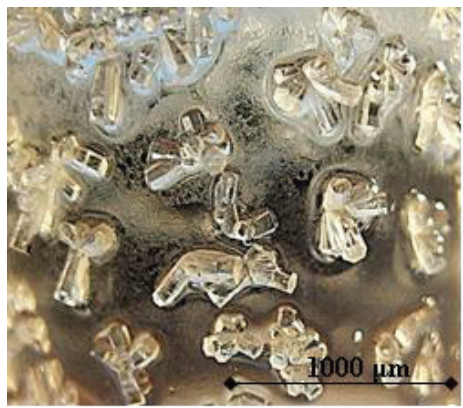

$a$

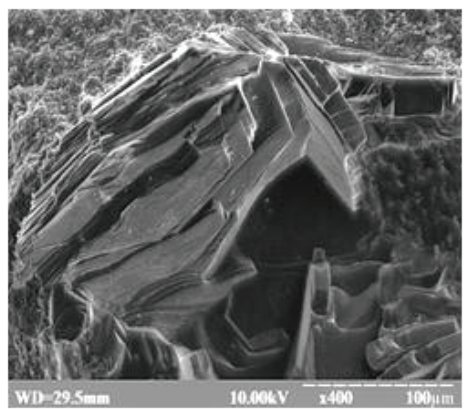

$c$

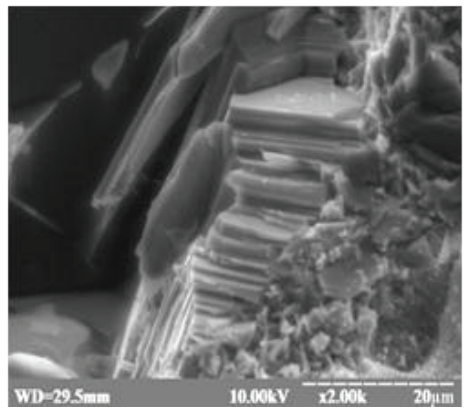

e

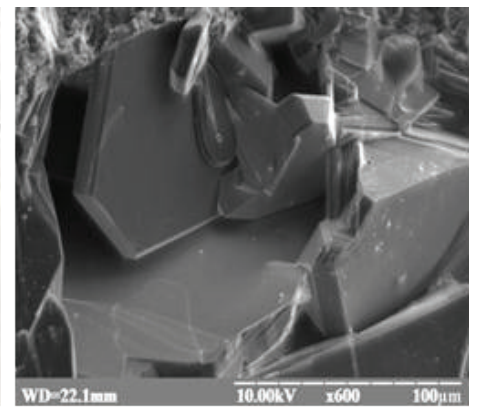

b

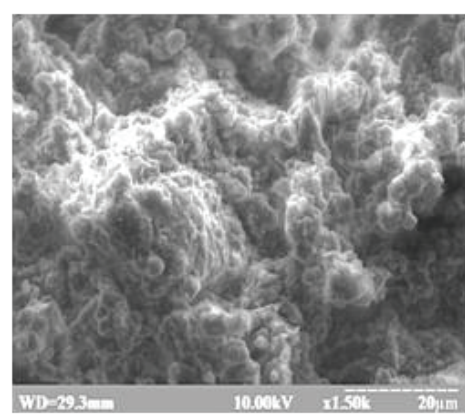

$d$

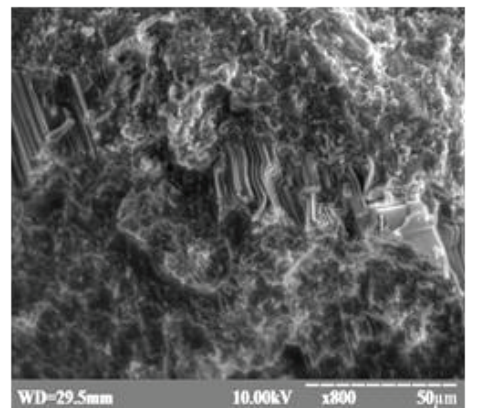

$f$

Fig. 3. Morphology of Portlandite crystals under different conditions of crystallization: $a$ - in the solution of $\mathrm{CaCl}_{2}$ and $\mathrm{NaOH} ; b$ - in water at $+4{ }^{\circ} \mathrm{C} ; c-$ in the solutions with $\mathrm{BO}_{4}{ }^{5-}$, $d-\mathrm{SiO}_{4}^{4-}, e, f-\mathrm{SO}_{4}^{2-}$ anions

During $\mathrm{CaO}$ hydration hardening that occurs at low supersaturation and superposition of geometric selection processes Portlandite is crystallized in the shape of hexagonal lamellae with the Van-der-Waals type of bond between adjacent layers in the direction of 0001 plane. While increasing temperature the great amount of Portlandite is formed as small aggregates of irregular shape. The mechanical strength of the system is determined by adhesion between individual crystals along cleavage planes 0001 due to Van-der-Waals intermolecular forces.

After five years of hydration the increase in crystals size is typical for the lime stone microstructure. Moreover, crystals transform into hexagonal lamella with simultaneous dilution of great aggregates of irregular shape occurred along cleavage plane 0001. Thus, crystals habit and sizes has the determinative effect on the formation of lime stone strength.

The investigations of crystals morphology show that Portlandite is crystallized as hexagonal lamellae in the presence of sulphate ions. Moreover, nucleation occurs around gypsum particles.

The strength of stone formed by Portlandite crystal phase is determined by intermolecular forces $(3.0-4.0 \mathrm{~kJ} / \mathrm{mol})$, which are weaker than ionic, covalent or coordination bonds. However such forces are universal, i. e. they occur between molecules or crystals at small distance and great amount of contacts leads to the high energy of adhesion. 
Van-der-Waals forces characterize electrostatic interaction between molecule shells consisting of oriental, inductive and dispersive components. Their dependence on distance is directly proportional one 1/r6. Non-polar molecules and particles take place in the dispersive interaction (London forces). This fact has the essential influence on the formation of Portlandite crystal structure.

The samples based on quicklime were hardened under wet conditions at the temperature of $+5{ }^{\circ} \mathrm{C}$. The results of physico-mechanical tests of the lime stone with high-dispersive gypsum hydrate show the increase in strength from $26.0 \mathrm{MPa}$ after 1 day to $39.5 \mathrm{MPa}$ after 720 days. With $5.0 \mathrm{wt} \%$ of gypsum dihydrate the compressive strength increases more rapidly. Thus, after 28 days the compressive strength is $42.5 \mathrm{MPa}$ and after 720 days $-48.0 \mathrm{MPa}$. This fact reveals the effect of $\mathrm{CaSO}_{4} \times 2 \mathrm{H}_{2} \mathrm{O}$ on Portlandite crystallization and formation of crystal structure of the lime stone.

Structure of the dispersions based on quicklime is formed due to recrystallization of colloidal coagulation-structuring systems because of their thermodynamic instability. In the presence of gypsum Portlandite crystals are formed as hexagonal lamellae, which width is 10-12 times wider than its thickness. As a result, the contact area between crystals and dispersive component of Vander-Waals forces increase and therefore the bending strength increases as well (Fig. 4).

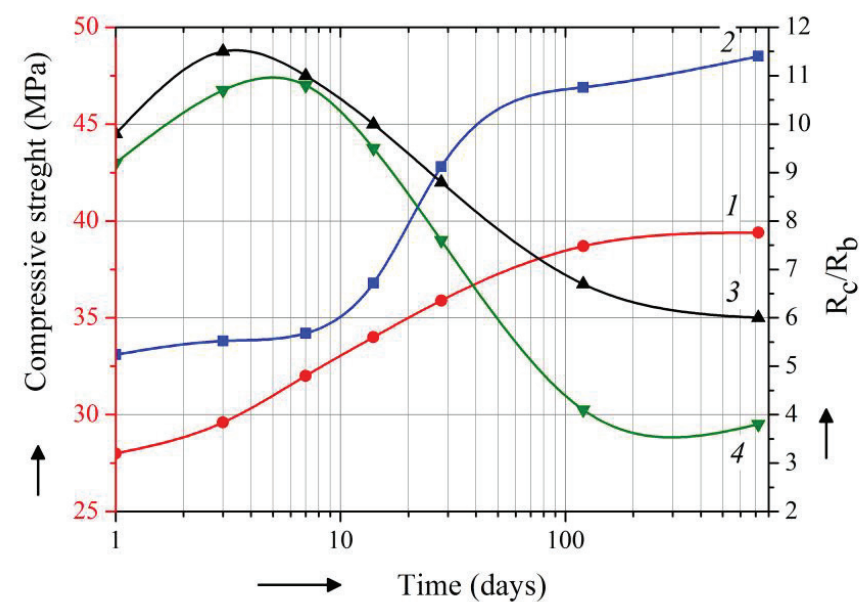

Fig. 4. Effect of gypsum dihydrate on the kinetics of lime stone strength:

$1-\mathrm{R}_{\mathrm{c}}$ without additives; $2-\mathrm{R}_{\mathrm{c}}$ with $5 \% \mathrm{CaSO}_{4} \cdot 2 \mathrm{H}_{2} \mathrm{O} ; 3-\mathrm{R}_{\mathrm{c}} / \mathrm{R}_{\mathrm{b}}$ without additives;

$4-\mathrm{R}_{\mathrm{c}} / \mathrm{R}_{\mathrm{b}}$ with $5 \% \mathrm{CaSO}_{4} \cdot 2 \mathrm{H}_{2} \mathrm{O} ; \mathrm{R}_{\mathrm{c}}$ - compressive strength, $\mathrm{R}_{\mathrm{b}}$ - bending strength

Under the influence of $\mathrm{SO}_{4}^{2-}$ anions the compression of diffusion layer around $\mathrm{Ca}(\mathrm{OH})_{2}$ colloidal micelles occurs, the thickness of water layer decreases and intermolecular interaction between hydrated particles increases. All these phenomena cause the appearance of internal compression strength which forms densely areas and joint hexagonal crystals of $\mathrm{Ca}(\mathrm{OH})_{2}$ around calcium oxide grains. At the same time water diffusion into internal capillaries of the lime particles is inhibited, the rate of $\mathrm{CaO}$ hydration and its three-dimensional deformations decrease.

Thus, morphology and habit of Portlandite crystals has an essential effect on the physico-mechanical properties of the lime stone. Portlandite lamellar crystals are characterized by high specific surface that leads to the increasing role of intermolecular interaction forces.

Under the provisions of modern chemistry and molecular physics the properties of solid matter (strength, hardness, melting point, and heat capacity) are determined by the nature of chemical bonds, their energy and peculiarities of crystal structure.

The mechanical strength of Portlandite is determined by the intermolecular interaction forces. Their nature is physical one and they occur at greater distance than other types of chemical bonds. The forces of intermolecular interaction have high values in the dispersion systems with large contact area between the particles and they are essential in the process of structure formation. The effect of dispersion component of intermolecular forces is caused by continuous movement of nuclei (oscillatory motion) and electrons (rotary motion). Thus a temporary shift of atomic orbitals relative to nucleus takes place and dipole is formed. The interaction between dipoles causes the appearance of dispersion forces. 
The increase in contact surface between Portlandite crystals is a determining factor of strength increase. Physico-chemical tests of the stone based on quicklime (Table 6) show the significant effect of temperature on the mechanical strength. Thus, the strength after 7 days of hardening is $37.3 \mathrm{MPa}$ at $+20{ }^{\circ} \mathrm{C}$ and after 28 days it is $50.0 \mathrm{MPa}$. At the investigation temperature of $400{ }^{\circ} \mathrm{C}$ the mechanical strength increases from $44.3 \mathrm{Mpa}$ after 7 days to $58.4 \mathrm{MPa}$ after 28 days. The reason is the absence of adsorption water in the Portlandite frame. Water has disjoining action and decreases the value of intermolecular forces and mechanical strength of the lime stone. At the temperature of liquid nitrogen $\left(-186{ }^{\circ} \mathrm{C}\right)$ we observe the slight decrease in the strength caused by dispersion component of Van-der-Waals forces, which depends on electric field of molecule dipoles. In nonpolar molecular lattices dipoles occur due to fluctuations, the number of which decreases with the decrease in temperature.

Table 6

Effect of investigation conditions on the physico-mechanical characteristics of the stone based on $\mathrm{CaO}$

\begin{tabular}{|c|c|c|c|}
\hline \multirow{2}{*}{ Investigation temperature } & \multicolumn{2}{|c|}{ Compressive strength, MPa after days } & \multirow{2}{*}{$\begin{array}{c}\text { Change of strength, } \\
\mathbf{R}_{7} / \mathbf{R}_{28}, \%\end{array}$} \\
\hline & 7 & 28 & \\
\hline$+20^{\circ} \mathrm{C}$ & 24.3 & 25.8 & +2.1 \\
\hline$+20{ }^{\circ} \mathrm{C}^{*}$ & 37.3 & 50.0 & +35.1 \\
\hline$+400{ }^{\circ} \mathrm{C}^{*}$ & 44.3 & 58.4 & +31.2 \\
\hline$-186{ }^{\circ} \mathrm{C}$ & 45.6 & 46.6 & +2.2 \\
\hline$-186^{\circ} \mathrm{C}^{*}$ & 43.1 & 45.0 & +4.4 \\
\hline
\end{tabular}

Thus, the important condition for hydration hardening is the formation of Portlandite crystals with lamellar shape with well-developed edges in the direction 0001. Such crystals are formed during $\mathrm{CaO}$ hydration in the solutions containing multiply charged anions, namely $\mathrm{BO}_{4}{ }^{2-}$ and $\mathrm{SO}_{4}{ }^{2-}$. As a result of formation of $\mathrm{Ca}(\mathrm{OH})_{2}$ lamellar habit small crystals their surface, contact area and bond strength increase. At the same time the value of lime expansion decreases in the early terms of hardening that leads to the increase in mechanical strength of the stone on its basis.

\section{Conclusions}

The strong lime stone is formed during $\mathrm{CaO}$ hardening due the directional influence on the kinetics of hydration heat release. It was established that under cryohydration conditions the interaction between $\mathrm{CaO}$ and $\mathrm{CO}_{2}$ of the air is energetically advantageous. The calcite amount in the hydration products increases at negative temperatures. The degree of $\mathrm{CaO}$ hydration increases till $98.0 \%$ and the stone strength achieves $12.5 \mathrm{MPa}$. At the same time the increase in strength takes place due to the intensified carbonization of the system.

The rate of $\mathrm{CaO}$ hydration varies owing to dispersion processes inhibition under the conditions of limited expansion, when microcrystals are associated and strong crystal frame is formed. Thus, the process of adaptation hardening takes place and great amount of parallelaccreted columnar crystals are formed with the width of 50-60 $\mu \mathrm{m}$ perpendicularly to the force limited expansion.

During $\mathrm{CaO}$ hydration the contraction plays the important role. Holding lime paste in the closed volume at rarefaction of $100-120 \mathrm{~mm} \mathrm{H}_{2} \mathrm{O}$ promotes hydration hardening because the maximum temperature does not exceed $55^{\circ} \mathrm{C}$.

$\mathrm{CaO}$ hydration hardening is accompanied by formation of Portlandite crystals of lamellar shape with well-developed edges in the direction 0001.They are formed in the solutions with multiply charged $\mathrm{BO}_{4}{ }^{2-}$ and $\mathrm{SO}_{4}{ }^{2-}$ anions. As a result of formation of $\mathrm{Ca}(\mathrm{OH})_{2}$ lamellar habit small crystals their surface, contact area and bond strength increase. The value of lime expansion decreases in the early terms of hardening that leads to the increase in mechanical strength of the stone on its basis.

Obtained results can be used to develop new types without clinker binders based on quicklime (lime-gypsum, lime-pozzolanic) with special properties (increased physical and mechanical characteristics, high water-retaining capacity, high corrosion resistance). 
Highly dispersed hydrated lime is widely used in the chemical industry, flue gas purification technology and the building industry as a component of lime paints and putties.

\section{References}

[1] Kasama, S. (1986). Hydration rate of quick lime. The Iron and Steel Institute of Japan, 72 (4), 91.

[2] Frey, M.-L., Kasig, W., Butenuth, G. (1995). Porosity and Slaking Rate of "Ideal Quicklimes" as Function of Chemical Composition, Mineral Paragenesis and Porosity of Geterophase Limestones. Wissenschaft und Umwelt, 1, 19-24.

[3] Kurdowski, W. (2014). Cement and Concrete Chemistry. New York London: Springer, 699. doi: $10.1007 / 978-94-007-7945-7$

[4] Lipunov, I. N., Kovel', M. S., Teploukhov, A. S., Tetykhin, V. V., Alikin, V. I. (2004). Kinetics and Thermodynamics of Hardening in Systems $\mathrm{MgO}-\mathrm{H}_{2} \mathrm{O}$ and $\mathrm{MgO}-\mathrm{MgCl}_{2}-\mathrm{H}_{2} \mathrm{O}$. Russian Journal of Applied Chemistry, 77 (4), 543-548. doi:10.1023/b:rjac.0000038663.55614.18

[5] Jaffel, H., Korb, J.-P., Ndobo-Epoy, J.-P., Morin, V., Guicquero, J.-P. (2006). Probing Microstructure Evolution during the Hardening of Gypsum by Proton NMR Relaxometry. The Journal of Physical Chemistry B, 110 (14), 7385-7391. doi: 10.1021/jp058276m

[6] Sychev, M. M. (1986). Inorganic Adhesives. Leningrad: Khimiya, 152.

[7] Sanytsky, M. A. (1990). Some Questions of the Crystal Chemistry of Cement Minerals. Kyiv: UMK VO, 64.

[8] Ramachandran, V. S., Sereda, P. J., Feldman, R. F. (1964). Mechanism of Hydration of Calcium Oxide. Nature, 201 (4916), 288-289. doi:10.1038/201288a0

[9] Hogewoning, S. (2006). The Relation between Limestone Properties and Quicklime Reactivity. Prague: 11th ILA-Congress, 11.

[10] Osin, B. V. (1954). Burnt Lime. Moscow: Strojizdat, 370.

[11] Rodríguez-Navarro, C. (2012). Binders in Historical Buildings: Traditional Lime in Conservation. Bilbao: Seminarios de la Sociedad Española de Mineralogía, 09, 91-112.

[12] Gallucci, E., Scrivener, K. (2007). Crystallisation of calcium hydroxide in early age model and ordinary cementitious systems. Cement and Concrete Research, 37 (4), 492-501. doi: 10.1016/j.cemconres.2007.01.001

[13] Yakymechko, Y. B., Chekanskyj, B. B. (2014). Effect of Physical-Chemical and Technological Factors on the Processes of Hydration Hardening of Calcium Oxide. ScienceRise, 5 (2), 83-89. doi: 10.15587/23138416.2014.31493

[14] Lõhmus, H., Räni, A., Kallavus, U., Reiska, R. (2008). A Trend to the Production of Calcium Hydroxide and Precipitated Calcium Carbonate with Defined Properties. The Canadian Journal of Chemical Engineering, 80 (5), 911-919. doi: 10.1002/cjce.5450800514

[15] Boynton, R. S. (1980). Chemistry and Technology of Lime and Limestone. New York: John Wiley and Sons, Inc., 578.

[16] Harris, K. D. M., Tremayne, M., Lightfoot, P., Bruce, P. G. (1994). Crystal Structure Determination from Powder Diffraction Data by Monte Carlo Methods. Journal of the American Chemical Society, 116 (8), 3543-3547. doi: 10.1021/ja00087a047

[17] Izumi, F., Young, R. A. (1993). The Rietveld Method. Oxford: Oxford University Press, 236-253.

[18] Uman, N. I., Svatovskaya, L. B., Ovchinnikova, V. P. (1998). Hardening Cement Minerals at Low Temperatures. Cement and its Applications, 5 (6), 26-28.

[19] Wolter, A., Luger, S., Schaefer, G. (2004). The Kinetics of the Hydration of Quicklime. Cement Lime Gypsum, 8, 60-69.

[20] Li, R., Zhang, X., Dong, H., Li, Q., Shuai, Z., Hu, W. (2015). Gibbs-Curie-Wulff Theorem in Organic Materials: A Case Study on the Relationship between Surface Energy and Crystal Growth. Advanced Materials, 28 (8), 1697-1702. doi: 10.1002/adma.201504370

[21] Yamazaki, Y., Gomi, T., Nakashima, Y. (1987). Expansive properties of new démolition agent. Tokio: Rev. 41st Gen. Meet. Cem. Assoc. Jap. Tech. Sess., 366-369.

[22] Galmarini, S., Aimable, A., Ruffray, N., Bowen, P. (2011). Changes in portlandite morphology with solvent composition: Atomistic simulations and experiment. Cement and Concrete Research, 41 (12), 1330-1338. doi: 10.1016/j.cemconres.2011.04.009

[23] Potgieter, J. H., Potgieter, S., De Waal, D. (2003). An empirical study of factors influencing lime slaking. Part II: lime constituents and water composition. Water SA, 29 (2), 157-160. doi:10.4314/wsa.v29i2.4850 